\title{
DESIGN OF A SERIOUS GAME FOR THE USE OF FOREIGN LANGUAGES: TOWARDS A RELEVANT DIDACTIC SYSTEM
}

\author{
Lizandro Becerra and Georges Antoniadis \\ LIDILEM Laboratory, Grenoble Alpes University, France \\ Bâtiment Stendhal CS40700-38058 Grenoble cedex 9
}

\begin{abstract}
Our reflection paper is the continuation of an ongoing R\&D project and focuses on the design and development of a didactic system for second language learning. This didactic system is based on the potential of the edutainment scenario for language learning. The system aims at practicing Spanish as a second language in a French secondary school. We consider that the combination of computer science, linguistics, language didactics and natural language processing (NLP) issues could offer operational solutions to language learners. We have therefore proposed an edutainment scenario capable of integrating the potential of serious games. The scenario has been designed and developed according to the linguistic needs of learners. In this paper, we propose to focus on four notions that make part of the design and development process of our edutainment scenario: serious games, teacher mediation, dictation and formative feedback.
\end{abstract}

\section{KEYWORDS}

Didactic System, Serious Games, Edutainment Scenario, Dictation, Feedback

\section{INTRODUCTION}

Advances in technology have changed learners' learning behaviors and reshaped teaching methods (Prensky, M. 2001). This has transformed the experience of learning processes in the teaching of foreign languages. As a result, language didactics, computer science, linguistics and natural language processing (NLP) are coming together to provide language learners with operational solutions. On the one hand, these systems are capable of offering didactic added value compared to conventional systems (Antoniadis, 2008). On the other hand, serious games have the potential to provide serious content in a playful way (Alvarez, J. \& Djaouti, D. 2012; Fenouillet, F. 2016; Oblinger, D.C. 2004). We have therefore proposed an edutainment scenario capable of integrating the potential of serious games in order to offer a relevant solution to second language learners. Thus, this issue is at the crossroads of two main areas concerning language learning: digital game-based language learning (DGBLL) and computer-assisted language learning (ICALL). First, we propose to explore some relevant elements of the available literature; second, we want to describe the adopted model of our system; third, we will see some important notions of our didactic system such as: serious games, teacher mediation, dictation and formative feedback; fourth, we want to explain our didactic system; and finally, we would also like to present some perspectives on the method and evaluation of our system.

\section{BACKGROUND}

Video games for language learning have been studied by various researchers (Chen, H. \& Yang, T. 2013; Yong-Ming. H. 2015; Schmoll, L. 2016; Loiseau, M., \& al 2016; Alyaz, Y. \& al, 2017) to name a few. The positive impact of the DGBLL tools has been reported in terms of improving learners' listening and writing skills (Alyaz, Y. \& al., 2017). On the basis of the available literature, there seems to be a scientific consensus that a game alone does not allow learning if it is not accompanied by pedagogical measures (O'Neil \& al., 2005). We also know that well-designed games are capable of motivating and engaging players by introducing them to compelling narratives and communicative complexity beyond what many traditional learning activities are capable of achieving (Reinhardt, J., \& al., 2014). 


\section{EDUTAINMENT SCENARIO}

The logic of designing a learning video game leads us to start from the learning objectives on which we will graft the gameplay more or less adapted to the learning needs of second language learners. To do this, we want to focus on the edutainment scenario model designed as a stage of linguistic performance and restitution of linguistic knowledge, based on alternative reality video games (Schmoll, L. 2016). The structure of an edutainment scenario takes into account both the framework of the interactive story (integrating the mechanisms of the game) and the pedagogical planning. Such a scenario is based on a first stage: the preparation sessions that would begin outside the serious game (tasks necessary for linguistic and playful understanding) and the second stage: the immersion stage with the serious game. On the one hand, our choice to adopt this model is justified because we consider the time spent using the serious game as a stage of language practice. Games that offer the possibility of transferring previously acquired knowledge to new problems, including those that require an adaptation of previous knowledge, with accompanying measures, should lead to better performance (O'Neil \& al. 2005). On the other hand, we chose the edutainment scenario because we seek to include the teacher as mediator; before, during and after the use of the technical system. We want to highlight four important elements of our edutainment scenario: serious play, mediation, dictation and feedback.

\subsection{Serious Game}

A serious game is a computer application, whose initial intention is to combine coherently the serious aspects (serious) in a neither exhaustive nor exclusive manner, with instruction, learning, communication or further on information, assorted with the playing aspect of video games (Alvarez, 2007). Thus, a serious game is a way to integrate an educational scenario into a video game. Concerning the serious game design, we considered the prerequisites necessary when designing a video game to expect a state of flow (optimal experience) from the player: a challenging activity, clear goals, clear feedback and the paradox of having control in an uncertain situation (Salen, K. \& Zimmerman, E. 2004).

\subsection{Teacher Mediation}

The notion of mediation/mediator is polysemic. At the level of the teacher, pedagogical mediation refers to the teacher's activity of relaying knowledge to learners. It therefore refers to the accompaniment of a human being by another human being. This notion of mediation is to be put in relation with the concept of the Proximal Development Zone (Vygotsky, 1967), which postulates that a subject progresses more rapidly in contact with a person of a higher level of development. In our project, the teacher retains a determining role because, in a pedagogical aim linked to the curriculum, play is not an end in itself (Musset, M. \& Thibert, R., 2009). For us, there is no education without mediation. Thus, the teacher's role is first and foremost that of a mediator; one who verbalizes experience and knowledge to ensure successful acquisition. In terms of ICT integration, the teacher can be a designer, expert, tutor and evaluator at the same time (Klein, A. \& Godinet H. 2000).

\subsection{Dictation}

We're concerned about dictation / transcription as a positive method for training linguistic skills: spelling, grammar and conjugation. Dictation / transcription as learning and training activities are not new; but what could be new to the considerations in our implementation is the combination with the potentiality of a serious game (Alyaz, Y. \& al., 2017), mediation and formative feedback. Dictation works in a number of different ways, depending on how long segments are. A good strategy is the scaffolding dictation; making chunks of different lengths in order to adapt them to the learner (Buck, G. 2001).

\subsection{Feedback}

We are interested in the potential for automatic, direct and immediate feedback. We want to help the learner to identify and correct the error himself when using the serious game (Chen, 2003). Instead of giving a binary response (correct or incorrect), it may be more interesting to provide automatic, direct and immediate feedback. 
Feedback in the ICALL system allows students to learn at their own pace and causes less frustration for learners (Kilickaya, 2007). Although more specific feedback can generally be better than less specific feedback. However, if feedback is too long or too complicated, many learners will simply ignore it, making it useless (Valerie J. S. 2008).

\section{EDUTAINMENT SCENARIO PROPOSITION}

We proposed an edutainment scenario adapted to the needs of second language learners (listening comprehension and writing skills). The target is Spanish as a second language (L2) in France. To do so, we designed five class sessions and a debriefing session; and we defined an immersion session corresponding to the serious game. The project is aimed at students of a French public secondary school (13 and 14 years old). The learners are at levels A1 and A2 of the CEFR (Common European Framework of Reference for Languages). As far as the theme to be dealt with is concerned, we have chosen the notion: Encounter with other cultures from the French curriculum (2018). When using the technical system, we aimed at dictation as a pedagogical and scaffolding method. We also proposed to help the learner to identify and correct the error himself through automatic formative feedback. In this way, any misspelled words will be automatically underlined.

\subsection{Design Model and Technical Structure}

We followed the steps of the PLOT model (Public, playful, Language Objectives and Tasks) since all the steps are in dialogue and therefore all are iterative (Schmoll, L. 2016). We defined the needs of the learners, then the gameplay (the story, the dialogues, the player's actions and the non-player's actions), after the specific linguistic objectives and finally the preparation tasks outside the technical system. We included the role of the teacher as tutor/mediator during the preparation sessions, the immersion game and the debriefing session. Concerning the technical aspects, we developed a 3D exploration video game with a First Person Perspective (FPP) in order to offer more field exploration elements and visibility. There is a Non Player Character (NPC) as a guide and speaker of the L2. In that way, player performs the right action (listening comprehension skills) and writes the right text (writing skills) in order to progress through the game. Regarding the structure of the scenario, we have opted for a nested event structure (Koster, 2005) that allows the subject to choose which area he will explore first and thus the corresponding task. The mission of the player/learner is to make an inventory of species in a virtual logbook. The player/learner must explore the terrain and perform actions such as searching for species, taking photos, freeing the animals (playful tasks) and writing down the characteristics of the species (language task). This information is provided by the NPC orally. The structure of the dialogues is still based on the Boolean type. However, it does not start from an instruction or a question formulated by the NPC, but from an event triggered by the player who initiates an interaction.

\section{PERSPECTIVES}

We would like to adopt the triangulation mixed method combining a quantitative and a qualitative approach (Creswell, J. W., et al., 2007). This, in order to answer the first research question; How could our didactic system provide operational and relevant solutions to the needs of language learners? We planned to collect and analyses quantitative and qualitative data and then compare the results in order to develop a complete understanding. In this way, we would like to test and experiment our first edutainment scenario for the use of Spanish as a second language. In order to evaluate our system, we propose to adopt an interactionist approach to foreign language learning, which would focus on five criteria: language learning potential, adaptation to the learner, focus on meaning, impact, authenticity and practicality (Chapelle, 2001). We chose this evaluation approach because for us evaluating the serious game is also to evaluate the preliminary instructions given by the teacher, the help he gives in class and the clarity of the restitution following the game session. Rather than questioning the possible performances for the learning of the serious game object itself, it is therefore necessary to seek the good adequacy of the tool to the needs of the teacher and the learners (All, A. \& al., 2014). 


\section{REFERENCES}

All A., Nuñez Castellar E. P. \& Van Loy, J. 2014. Measuring Effectiveness in Digital Game-Based Learning: A Methodological Review, International Journal of Serious Games, vol. 1, ${ }^{\circ} 2$.

Alvarez, J. 2007. Du jeu vidéo au Serious game. Approches culturelle, pragmatique et formelle. Thèse de Doctorat en Science de la communication et de l'information. Université de Toulouse II et III.

Alvarez, J. \& Djaouti, D. 2012. Introduction au serious game. 2e Revue et augmentée. Questions Théoriques, Paris.

Alyaz, Y., Dorothea S. W., Esim, G. A. 2017. Study on Using Serious Games in Teaching German as a Foreign Language. Journal of Education and Learning; Vol. 6.

Antoniadis, G. 2008. Du TAL et son apport aux systèmes d'apprentissage des langues. Contributions. Spécialité : Industries de la langue. Habilitation à diriger des recherches, laboratoire LIDILEM. Université Stendhal - Grenoble 3.

Buck, G. 2001. Assessing listening. Cambridge: CUP.

Chapelle, C. A. 2001. Computer applications in second language acquisition. New York: Cambridge.

Chen, J. 2007. Flow in games (and everything else). In Communications of the ACM, vol. 50, n ${ }^{\circ}$. 31-34. https://www.jenovachen.com/flowingames/p31-chen.pdf

Creswell, J. W. \& Plano Clark, V. L. 2007. Designing and conducting mixed methods research. Thousand Oaks, CA: Sage.

Fenouillet, F. 2016. Les théories de la motivation. Dunod, Paris.

Guichon, N. 2012. Vers l'intégration des TIC dans l'enseignement des langues. Didier. Paris.

Kilickaya, F. 2007. The Effect of Computer Assisted Language Learning on Turkisk Learners. Achievement on The TOEFL Exam.

Klein A. \& Godinet H. 2000. The teacher as a mediator in a networked society. In: Watson D.M., Downes T. (eds) Communications and Networking in Education. IFIP - The International Federation for Information Processing, vol 35. Springer, Boston, MA. pp 157-164.

Koster, R. 2005. A grammar of gameplay - Game atoms: can games be diagrammed? Sony Online Entertainment. Futurevision. Game Developers Conference. San Francisco.

Musset, M. \& Thibert, R. 2009. Quelles relations entre jeu et apprentissages à l'école ? Une question renouvelée. Dossier d'actualité de la VST, $\mathrm{n}^{\circ} 48$.

Oblinger, D.G. 2004. The Next Generation of Educational Engagement. Journal of Interactive Media in Education. p. Art. 10.

O’Neil, H. F., Wainess, R. \& Baker, E. L. 2005. Classification of learning outcomes: Evidence from the computer games literature. The Curriculum Journal, 16(4).

Prensky, M. 2001. Digital Natives, Digital Immigrants. On the Horizon, vol. 9, n ${ }^{\circ}$, octobre.

Reinhardt, J., Warner, C., Lange, K.: Digital games as practices and texts: New literacies and genres in an L2 German classroom. University of Arizona (USA). Calico Monograph series. Volume 12. Chapter 7, 159-177 (2014).

Salen, K. \& Zimmerman, E. 2004. Rules of Play - Game Design Fundamentals. Massachusetts London, England: The MIT Press Cambridge.

Schmoll, L. 2016. Concevoir un scénario de jeu vidéo sérieux pour l'enseignement-apprentissage des langues ou comment dominer un oxymore. Thèse de doctorat en Sciences du langage - linguistique. Université de Strasbourg.

Valerie J. S. 2008. Focus on Formative Feedback. Review of Educational Research, vol. 78, 1: pp. 153-189. , First Published March 1.

Vygotski, Lev S. 1967. Play and its role in the mental development of the child. In Soviet psychology, vol. V, n³, printemps. 